\title{
Mechanistic Study of Ruthenium(III) Catalyzed Oxidation of Cyclohexanone by Acidic Bromate
}

\author{
Yasir Arafat Lone ${ }^{1,2^{*}}$, Masood Ayoub Kaloo ${ }^{2,3^{*}}$, Faizan Danish Khaleel² \\ ${ }^{1}$ Department of Chemistry, Lovely Professional University, Phagwara, India \\ ${ }^{2}$ Department of Chemistry, Government Degree College, Shopian, India \\ ${ }^{3}$ Department of Chemistry, Islamic University of Science and Technology, Awantipora, India \\ Email: *Arafatyasir786@gmail.com, makandchem@gmail.com
}

How to cite this paper: Lone, Y.A., Kaloo, M.A. and Khaleel, F.D. (2018) Mechanistic Study of Ruthenium(III) Catalyzed Oxidation of Cyclohexanone by Acidic Bromate. Journal of Surface Engineered Materials and Advanced Technology, 8, 27-36. https://doi.org/10.4236/jsemat.2018.82003

Received: November 25, 2017

Accepted: February 26, 2018

Published: March 1, 2018

Copyright $(9) 2018$ by authors and Scientific Research Publishing Inc. This work is licensed under the Creative Commons Attribution International License (CC BY 4.0).

http://creativecommons.org/licenses/by/4.0/

\section{(c) (i) Open Access}

\begin{abstract}
In this work, kinetics and mechanism of $\mathrm{Ru}(\mathrm{III})$ catalyzed oxidation of cyclohexanone by acidified solution of potassium bromate has been studied. Present study employ mercuric acetate $\mathrm{Hg}(\mathrm{OAc})_{2}$ as a scavenger for $\mathrm{Br}^{-}$ion to prevent parallel oxidation by bromine. The kinetics and mechanism have also been studied in the temperature range of $30^{\circ} \mathrm{C}-45^{\circ} \mathrm{C}$. The reaction exhibits first order kinetics with respect to $\mathrm{Ru}$ (III), while zero order kinetics with respect to $\mathrm{KBrO}_{3}$ and $\mathrm{HClO}_{4}$. The influence of $\mathrm{Hg}(\mathrm{OAc})_{2}$ and ionic strength on the rate of reaction was found to be insignificant. Positive effect in the reaction mixture was also observed upon addition of chloride ion; while as the negative effect was revealed with acetic acid. A suitable mechanism in conformity with the kinetic observations has been proposed and the rate law is derived on the basis of obtained data. The various activation parameters such as energy of activation $\left(\Delta \mathrm{E}^{\star}\right)$, Arrhenius factor (A), entropy of activation $\left(\Delta S^{*}\right)$ were calculated from the rate measurements at $30^{\circ} \mathrm{C}, 35^{\circ} \mathrm{C}-40^{\circ} \mathrm{C}$ and $45^{\circ} \mathrm{C}$.
\end{abstract}

\section{Keywords}

Kinetics, Ru (III), Oxidation, Ketone, Bromate, Acidic, Order

\section{Introduction}

Catalysis by transition metals plays a significant role in understanding the mechanism of redox reactions. Ruthenium(III) acts as an efficient catalyst in many redox reactions. Besides this, a number of oxidants like $\mathrm{N}$-bromoacetimde (NBA) [1] [2], N-bromosuccinimide (NBS) [3] [4], Sodium periodiate $\left(\mathrm{NaIO}_{4}\right)$ [5] [6] have been used incorporation with transition metal ions like Osmium(VIII), Iridium(III), Ruthenium(VIII), etc. [7] [8] [9] for oxidation of var- 
ious compounds. The kinetics of redox reactions involving such catalysts and oxidants has been extremely investigated. However, a scant attention has been paid towards use of $\mathrm{KBrO}_{3}$ as an oxidant in various metal catalyzed reactions [10] [11]. The utility of ruthenium(III) chloride as a homogeneous catalyst has been reported by several workers [12] [13], but scant attention has been paid to explore catalytic role of ruthenium(III) chloride with potassium bromate as an oxidant. This fact prompted us to undertake the present investigation which consists of $\mathrm{Ru}(\mathrm{III})$ catalyzed oxidation of cyclohexanone by bromate in acidic medium.

\section{Materials and Methods}

\subsection{Solutions and Reagents}

The solution of oxidant $\mathrm{KBrO}_{3}(\mathrm{CDH})$, Cyclohexanone (CDH), $\mathrm{KCl}(\mathrm{CDH})$ and perchloric acid $(\mathrm{CDH})$ were prepared by dissolving its weighed sample in distilled water.

- The solution of Ruthenium trichloride (Loba) was prepared in $\mathrm{HCl}$ of known strength.

- $\mathrm{Hg}(\mathrm{OAc})_{2}(\mathrm{CDH})$ solution was prepared by dissolving it in $10 \% \mathrm{CH}_{3} \mathrm{COOH}$ solution in distilled water.

- $4 \%$ solution of $\mathrm{KI}(\mathrm{CDH})$ was prepared by dissolving its sample in distilled water.

$5.1 \%$ starch $(\mathrm{CDH})$ solution was prepared a fresh each day.

\subsection{Methodology}

A thermo stated water bath was used to achieve and maintain the desired temperature within $\pm 0.1^{\circ} \mathrm{C}$. Requisite volume of all reagents including substrate, were taken in a reaction vessel and temperature was maintained around $35^{\circ} \mathrm{C} \pm$ $0.1^{\circ} \mathrm{C}$ for thermal equilibrium. Here measured volume of $\mathrm{KBrO}_{3}$ solution was poured rapidly into the reaction vessel which was also maintained separately at similar temperature. The kinetics was followed by examining desired portions of reaction mixture for $\mathrm{KBrO}_{3}$ iodometrically using starch as indicator after suitable time intervals. In all our titration experiments, micro burettes were used.

\subsection{Stoichiometry}

The stoichiometry of the reaction was determined by equilibrating varying ratios of $\left[\mathrm{KBrO}_{3}\right]$ to cyclohexanone at $35^{\circ} \mathrm{C}$ for $48 \mathrm{hrs}$. Estimation of unconsumed $\mathrm{KBrO}_{3}$ revealed that one mole of the substrate consumes two moles of the oxidant. The product analysis by conventional method [12] shows the formation of diketone after the reaction. The stoichimetric determination indicated the overall reaction (Scheme 1).

\section{Results and Discussions}

In order to propose a probable reaction mechanism for $\mathrm{Ru}(\mathrm{III})$ catalyzed 


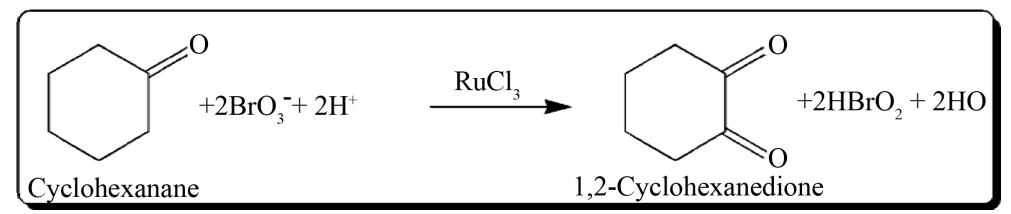

Scheme 1. Oxidation of cyclohexanone to 1,2-cyclohexanedione.

oxidation of cyclohexanone by acidic bromate, it is necessary to study the effect of concentration of different reactants on the rate of reaction. The kinetics of the $\mathrm{Ru}$ (III) catalyzed oxidation of cyclohexanone by acidic bromate was investigated at several initial reactant concentrations (Table A1, Supplementary Information). Here, first order kinetics was observed with respect to the catalyst, $\mathrm{Ru}(\mathrm{III})$. A plot of (-dc/dt) versus Ru (III) (Figure A1, Supplementary Information) confirms its first order kinetics with respect to the catalyst. It is also confirmed by plotting a graph between $8+\log (-\mathrm{dc} / \mathrm{dt})$ and $6+\log [\mathrm{Ru}(\mathrm{III})]$ for oxidation of cyclohexanone at $35^{\circ} \mathrm{C}$ (Figure A2, Supplementary Information). It is clear from the Table A1, (Supplementary Information) that increase in concentration of substrate resulted in the increase of $(-\mathrm{dc} / \mathrm{dt})$ values. In addition to these, graph plotted between $(-\mathrm{dc} / \mathrm{dt})$ values against (cyclohexanone) (Figure A3, Supplementary Information) gives a straight line which confirms a unity order of reaction with respect to substrate (cyclohexanone). It is also clear from the Table A1, (Supplementary Information) that upon varying the concentration of $\mathrm{KBrO}_{3}$, constant value of $(-\mathrm{dc} / \mathrm{dt})$ is achieved. Hence it is a zero order of reaction with respect to $\mathrm{KBrO}_{3}$.

Kinetic results obtained on varying concentration of hydrogen ions indicate negligible effect of $\left[\mathrm{H}^{+}\right]$ions. Besides, an insignificant effect was observed upon variation of ionic strength of the medium. Moreover, effect on the reaction rate determined by varying the mercuric acetate concentration is also clear from kinetic data (Table A2, Supplementary Information). As negligible effect of mercuric acetate was observed, hence it excludes the possibility of its involvement either as catalyst or as an oxidant. Thus it acts as a scavenger [14] [15] for any bromide ions formed in the reaction. Similarly, addition of chloride ions to the reaction mixture influences the velocity of this reaction, and also possesses positive effect. Apart from $\mathrm{Cl}^{-}$, addition of acetic acid shows negative effect on the rate of reaction. With the help of rate measurements around $30^{\circ} \mathrm{C}-45^{\circ} \mathrm{C}$, specific rate constants were used to plot $\log (-\mathrm{dc} / \mathrm{dt})$ versus $1 / \mathrm{T}$ (Figure A4, Supplementary Information), which came to be linear. The values of energy of activation $\left(\Delta \mathrm{E}^{*}\right)$ and free energy of activation $\left(\Delta \mathrm{G}^{*}\right)$, were calculated from the rate measurements at $30^{\circ}, 35^{\circ}, 40^{\circ}$ and $45^{\circ} \mathrm{C}$, and the corresponding values have been mentioned in the Table A3 (Supplementary Information). From the literature, it is well established that $\mathrm{Ru}(\mathrm{III})$ chloride gives a number of possible chloro species, and their existence is totally dependent on $\mathrm{pH}$ of the medium. And it also well reported that $\mathrm{Ru}(\mathrm{III})$ exists in an equilibrium under the experimental $\mathrm{pH}$ range $10-12$ [16]. Besides these, the data obtained data under the 
mentioned conditions indicate that addition of chloride ion has a probable effect on the reaction velocity.

The above observations lead us to suggest the following reaction mechanism in the title reaction.

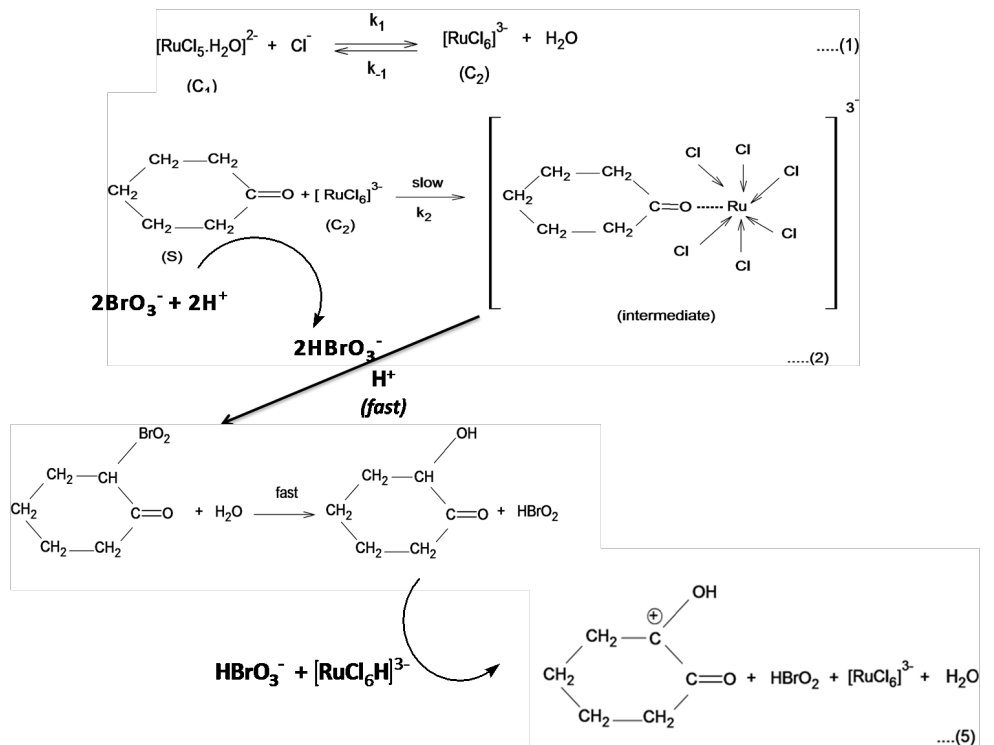

Now on the basis of above proposed reaction steps, and further applying steady state approximation, it yields rate law in terms of loss of concentration of potassium bromated:

$$
\begin{aligned}
& \frac{-\mathrm{d}\left[\mathrm{BrO}_{3}\right]}{\mathrm{dt}}=\mathrm{k} 2\left[\mathrm{C}_{2}\right][\mathrm{S}] \\
& \frac{-\mathrm{d}\left[\mathrm{BrO}_{3}\right]}{\mathrm{dt}}=\frac{\mathrm{k}_{2} \mathrm{k}_{1}[\mathrm{Ru}(111)]_{\mathrm{T}}[\mathrm{C}][\mathrm{S}]}{\mathrm{k}_{-1}+\mathrm{k}_{1}\left[\mathrm{C}^{-}\right]} \\
& \text {Where } \quad[\mathrm{Ru}(\mathrm{III})]_{\mathrm{T}}=\left[\mathrm{C}_{1}+\left[\mathrm{C}_{2}\right]\right.
\end{aligned}
$$

The rate law is in agreement with all observed kinetics. The proposed mechanism is in consistent with the activation parameters given in Table A1 (Supplementary Information). The high positive values of change in free energy of activation $\left(\Delta G^{*}\right)$ indicates highly solvated transition state, while fairly high negative values of change in entropy of activation $\left(\Delta \mathrm{S}^{*}\right)$ suggest the formation of an activated complex with reduction in the degree of freedom of molecules.

\section{Conclusion}

The experimental results obtained in this work revealed that the reaction rate 
doubles upon doubling the concentration of the catalyst $[\mathrm{Ru}(\mathrm{III})]$. The rate law is in conformity with all kinetic observations and the proposed mechanistic steps are supported by the negligible effect of ionic strength. Negative effect of acetic acid addition signifies a positive dielectric effect. From these investigations, it is concluded that $\mathrm{HBrO}_{3}[13]$ and $\left[\mathrm{RuCl}_{6}\right]^{-3}$ are the reactive species of $\mathrm{KBrO}_{3}$ and $\mathrm{Ru}(\mathrm{III})$ chloride respectively in acidic medium.

\section{Acknowledgements}

Y. Arafat highly acknowledges faculty members of department of chemistry LPU and GDC, for their support during and kind suggestions. M. A. Kaloo gratefully acknowledges the DST, New Delhi for DST-INSPIRE Faculty Award (DST/ INSPIRE/04/2016/000098).

\section{References}

[1] Srivastava, S. and Sharma, R.K. (2006) Mechanistic Study of Ruthenium(III) Catalysed Oxidation of Leucine by Alkaline N-Bromoacetamide. Oxidation Communication, 2, 343-349.

[2] Srivastava, S. and Singh, S. (2004) Kinetic Study of Ruthenium(III) Catalyzed Oxidation of Proline by Bromate in Acidic Medium. Journal of Indian Chemical Society, 18, 295.

[3] Srivastava, S., Kumar, A. and Srivastava, P. (2006) A Kinetic Study of RuIII Catalyzed Oxidation of Maltose by Potassium Bromate in Alkaline Medium. Journal of Indian Chemical Society, 83, 347-350.

[4] Srivastava, S., Sharma, R.K. and Singh, S (2006) Kinetics and Mechanism of Iridium(III) Catalyzed Oxidation of Some Cyclic Alcohols by Potassium Bromate in Acidic Medium. Journal of Indian Chemical Society, 83, 282-287.

[5] Singh, A., Singh, S., Singh, A. and Singh, B. (2005) Mechanistic Study of Osmium(VIII) Promoted Oxidation of Crotonic Acid by Aqueous Alkaline Solution of Potassium Bromate. Transition Metal Chemistry, 30, 610-615.

https://doi.org/10.1007/s11243-005-3850-8

[6] Ahmed, I. and Ashraf, C.M (1979) Kinetics and Mechanism of Palladium (II) Chloride Catalyzed Oxidation of Allyl Alcohol by Potassium Hexacyanoferrate(III). International Journal of Chemical Kinetics, 11, 813-819. https://doi.org/10.1002/kin.550110802

[7] Sergar, V., Veeresh, T.M. and Nandibewoor, S.T (2007) Osmium(VIII) Catalysed Oxidation of 1-leucine by a New Oxidant, Diperiodatoargentate(III) in Aqueous Alkaline Medium. Journal of Molecular Catalysis: A Chemical, 271, 253-260. https://doi.org/10.1016/j.molcata.2007.03.007

[8] Srivastava, S., Singh, S. and Srivastava, P. (2008) Ruthenium(VIII) Catalyzed Oxidation of Some Cyclic Alcohols by Sodium Periodate in Alkaline Medium. Asian Journal of Chemistry, 20, 317-323.

[9] Singh, P., Raghuvanshi, R. and Raghuvanshi, R. (2009) Comparative Study on $\mathrm{Pd}(\mathrm{II})$ and $\mathrm{Ru}(\mathrm{III})$ Catalyzed Oxidation of $\alpha$-amino- $\beta$-hydroxypropionic Acid (dl-serine) by Acid Bromate: A Kinetic Study. Oriental Journal of Chemistry, 25, 1047-1052.

[10] Srivastava, S., Khare, P., Singh, S. and Srivastava, S. (2008) Ru(III) and Ir(III) Catalysed Oxidation of Citric Acid by N-bromosuccinimide. A Comparative Kinetic 
Study. Oxidation Communications, 31, 327-334.

[11] Srivastava, S., Awasthi, A. and Singh, K. (2004) Ruthenium (III) Catalyzed Oxidation of Cyclopentanol and Cyclohexanol by $\mathrm{N}$-Bromoacetamide. International Journal of Chemical Kinetics, 37, 275-281. https://doi.org/10.1002/kin.20076

[12] Fiegl, F. (1996) Spot Test in Organic Analysis. Elsevier, New York, 325.

[13] Srivastava, S. and Singh, B. (1991) Kinetics and Mechanism of Ruthenium Tetroxide Catalysed Oxidation of Cyclic Alcohols by Bromate in a Base. Transition Metal Chemistry, 16, 466. https://doi.org/10.1007/BF01129466

[14] Subramanian, V.N. and Thigarajan, V. (1969) Mechanism of Oxidation of Alcohols with N-Bromo succinimide. Canadian Journal of Chemistry, 47, 694. https://doi.org/10.1139/v69-108

[15] Bailer, J.C. (1964) Partial Resolution of Diamines, Amino Acids, and Dicarboxylic Acids through Coordination with Optically Active Ligands. Chemistry of Coordination Compounds, Reinhold, New York, 4.

[16] Reddy, C.S. and Sundaram, E.V (1989) Mechanism of Acid Bromate Oxidation of Trans Mono-Substituted Cinnamic Acids: Structure Reactivity Correlation-A Non-Linear Hammett's Plot. Tetrahedron, 45, 2109-2126.

https://doi.org/10.1016/S0040-4020(01)80072-7 


\section{Supplementary Information}

Table A1. Effect of variation of reactants on the reaction rate.

\begin{tabular}{|c|c|c|c|c|c|}
\hline $\begin{array}{l}{[\text { Substrate }] \times} \\
10^{2} \mathrm{~mol} \cdot \mathrm{dm}^{-3}\end{array}$ & $\begin{array}{c}{\left[\mathrm{KBrO}_{3}\right] \times 10^{3}} \\
\mathrm{~mol} \cdot \mathrm{dm}^{-3}\end{array}$ & $\begin{array}{c}\mathrm{Ru}(\mathrm{III}) \times 10^{-6} \\
\mathrm{~mol} \cdot \mathrm{dm}^{-3}\end{array}$ & $\begin{array}{c}{\left[\mathrm{HClO}_{4}\right] \times 10^{3}} \\
\mathrm{~mol} \cdot \mathrm{dm}^{-3}\end{array}$ & $\begin{array}{c}(-\mathrm{dc} / \mathrm{dt}) \times 10^{7} \\
\mathrm{~mol} \cdot \mathrm{dm}^{-3} \cdot \mathrm{s}^{-1}\end{array}$ & $\mathrm{k}_{1} \times 10^{4} \mathrm{~s}^{-1}$ \\
\hline 0.33 & 1 & 96 & 1 & 1.2 & 1.29 \\
\hline 0.4 & 1 & 96 & 1 & 1.38 & 1.5 \\
\hline 0.5 & 1 & 96 & 1 & 1.75 & 1.94 \\
\hline 0.66 & 1 & 96 & 1 & 2.28 & 2.62 \\
\hline 1 & 1 & 96 & 1 & 3.4 & 4.14 \\
\hline 2 & 1 & 96 & 1 & 6.66 & 10.24 \\
\hline 1 & 0.83 & 96 & 1 & 3.5 & 5.14 \\
\hline 1 & 1 & 96 & 1 & 3.4 & 4.14 \\
\hline 1 & 1.25 & 96 & 1 & 3.5 & 3.39 \\
\hline 1 & 1.66 & 96 & 1 & 3.43 & 2.48 \\
\hline 1 & 2.5 & 96 & 1 & 3.33 & 1.58 \\
\hline 1 & 3.33 & 96 & 1 & 3.34 & 1.19 \\
\hline 1 & 1 & 9.6 & 1 & 0.4 & 0.41 \\
\hline 1 & 1 & 24 & 1 & 0.92 & 0.99 \\
\hline 1 & 1 & 48 & 1 & 1.75 & 1.92 \\
\hline 1 & 1 & 72 & 1 & 2.6 & 2.98 \\
\hline 1 & 1 & 96 & 1 & 3.4 & 4.14 \\
\hline 1 & 1 & 120 & 1 & 4.3 & 5.73 \\
\hline 1 & 1 & 96 & 0.83 & 3.5 & 4.26 \\
\hline 1 & 1 & 96 & 1 & 3.4 & 4.14 \\
\hline 1 & 1 & 96 & 1.25 & 3.42 & 4.17 \\
\hline 1 & 1 & 96 & 1.66 & 3.45 & 4.2 \\
\hline 1 & 1 & 96 & 2.5 & 3.55 & 4.32 \\
\hline 1 & 1 & 96 & 5 & 3.33 & 4.06 \\
\hline
\end{tabular}

$[\mathrm{Ru}(\mathrm{III})]=96.00 \times 10^{-6} \mathrm{M},[\mathrm{KCl}]=1.00 \times 10^{-3} \mathrm{M}\left[\mathrm{Hg}(\mathrm{OAc})_{2}\right]=1.25 \times 10^{-3} \mathrm{M}$.

Table A2. Effect of variation of chloride ion, mercury (II) acetate and sodium perchlorate at $35^{\circ} \mathrm{C}$.

\begin{tabular}{|c|c|c|c|c|}
\hline \multirow{2}{*}{$\begin{array}{c}{[\mathrm{KCl}] \times 10^{-3}} \\
\mathrm{~mol} \cdot \mathrm{dm}^{-3}\end{array}$} & {$\left[\mathrm{Hg}(\mathrm{OAc})_{2}\right.$} & {$\left[\mathrm{NaClO}_{4}\right]$} & \multirow{2}{*}{$\begin{array}{c}(-\mathrm{dc} / \mathrm{dt}) \times 10^{7} \\
\mathrm{~mol} \cdot \mathrm{dm}^{-3} \cdot \mathrm{s}^{-1}\end{array}$} & \multirow{2}{*}{$\mathrm{k}_{1} \times 10^{4} \mathrm{~s}^{-1}$} \\
\hline & $\times 10^{3} \mathrm{~mol} \cdot \mathrm{dm}^{-3}$ & $\times 10^{3} \mathrm{~mol} \cdot \mathrm{dm}^{-3}$ & & \\
\hline 0.83 & 1.25 & - & 3.25 & 3.91 \\
\hline 1 & 1.25 & - & 3.4 & 4.14 \\
\hline 1.25 & 1.25 & - & 3.5 & 4.26 \\
\hline 1.66 & 1.25 & - & 3.63 & 4.48 \\
\hline
\end{tabular}




\section{Continued}

\begin{tabular}{ccccc}
\hline 2.5 & 1.25 & - & 3.8 & 4.75 \\
5 & 1.25 & - & 4 & 5.06 \\
1 & 0.83 & - & 3.5 & 4.26 \\
1 & 1 & - & 3.33 & 4.01 \\
1 & 1.25 & - & 3.4 & 4.14 \\
1 & 1.66 & - & 3.6 & 4.33 \\
1 & 2.5 & - & 3.4 & 4.09 \\
1 & 5 & - & 3.5 & 4.21 \\
1 & 1 & 1 & 3.5 & - \\
1 & 1.25 & 2 & 3.43 & - \\
1 & 1.25 & 2.5 & 3.33 & - \\
1 & 1.25 & 5 & 3.5 & - \\
1 & 1.25 & 10 & 3.42 & - \\
1 & 1.25 & 12.5 & 3.52 & - \\
\hline
\end{tabular}

$[\mathrm{Ru}(\mathrm{III})]=96.00 \times 10^{-6} \mathrm{M},[$ cyclohexanone $]=2.00 \times 10^{-2} \mathrm{M}\left[\mathrm{HClO}_{4}\right]=1.00 \times 10^{-3} \mathrm{M},\left[\mathrm{KBrO}_{3}\right]=1.00 \times$ $10^{-3} \mathrm{M}$.

Table A3. Activation parameters for $\mathrm{Ru}(\mathrm{III})$ catalyzed oxidation of cyclohexanone by acidic bromated.

\begin{tabular}{ccc}
\hline Activation parameters & Temp $/{ }^{\circ} \mathrm{C}$ & Cyclohexanone \\
\hline $\mathbf{k}_{\mathrm{r}} \times 10^{4} \mathrm{~s}^{-1}$ & 30 & 2.81 \\
$\mathbf{k}_{\mathrm{r}} \times 10^{4} \mathrm{~s}^{-1}$ & 35 & 4.14 \\
$\mathbf{k}_{\mathrm{r}} \times 10^{4} \mathrm{~s}^{-1}$ & 40 & 6.59 \\
$\mathbf{k}_{\mathrm{r}} \times 10^{4} \mathrm{~s}^{-1}$ & 45 & 9.88 \\
$\operatorname{log~A}$ & --- & 8.8 \\
$\Delta \mathrm{E}^{*}\left(\mathrm{kj} \cdot \mathrm{mol}^{-1}\right)$ & --- & 54.77 \\
$\Delta \mathrm{G}^{*}\left(\mathrm{kj} \cdot \mathrm{mol}^{-1}\right)$ & 35 & 79.62 \\
$\Delta \mathrm{H}^{*}\left(\mathbf{k j} \cdot \mathrm{mol}^{-1}\right)$ & 35 & 73.7 \\
$\Delta \mathbf{S}^{*}\left(\mathrm{JK}^{-1} \cdot \mathrm{mol}^{-1}\right)$ & 35 & -19.21
\end{tabular}




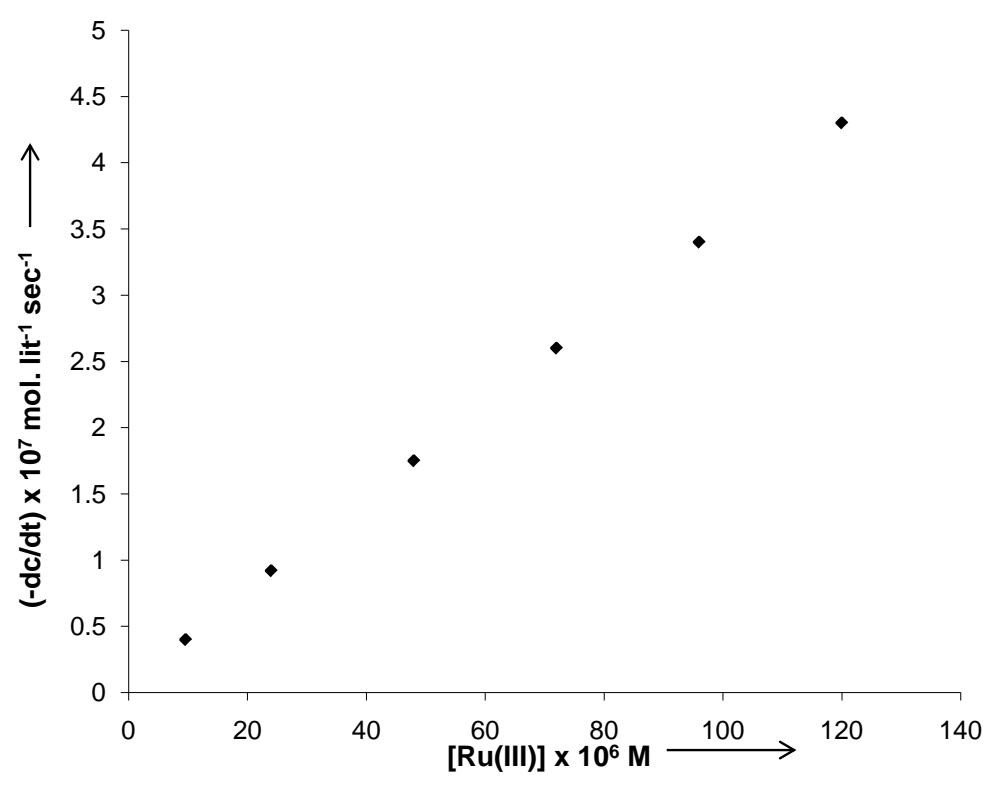

Plot between (-dc/dt) and $[\mathrm{Ru}(\mathrm{III})]$ at $35^{\circ} \mathrm{C}$.

$\begin{array}{lll}{\left[\text { cyclohexanone }=1.00 \times 10^{-2} \mathrm{M}\right.} & {[\mathrm{KCl}]=1.00 \times 10^{-3} \mathrm{M}} \\ {\left[\mathrm{Hg}(\mathrm{OAc})_{2}\right]} & =1.25 \times 10^{-3} \mathrm{M} & {\left[\mathrm{KBrO}_{3}\right]=1.00 \times 10^{-3} \mathrm{M}} \\ {\left[\mathrm{HClO}_{4}\right]=1.00 \times 10^{-3} \mathrm{M}} & \end{array}$

Figure A1. Plot between $(-\mathrm{dc} / \mathrm{dt}) \times 10^{-7} \mathrm{ML}^{-1} \cdot \mathrm{s}^{-1}$ and $[\mathrm{Ru}(\mathrm{III})] \times 10^{-6} \mathrm{M}$ for oxidation of cyclohexanone at $35^{\circ} \mathrm{C}$.

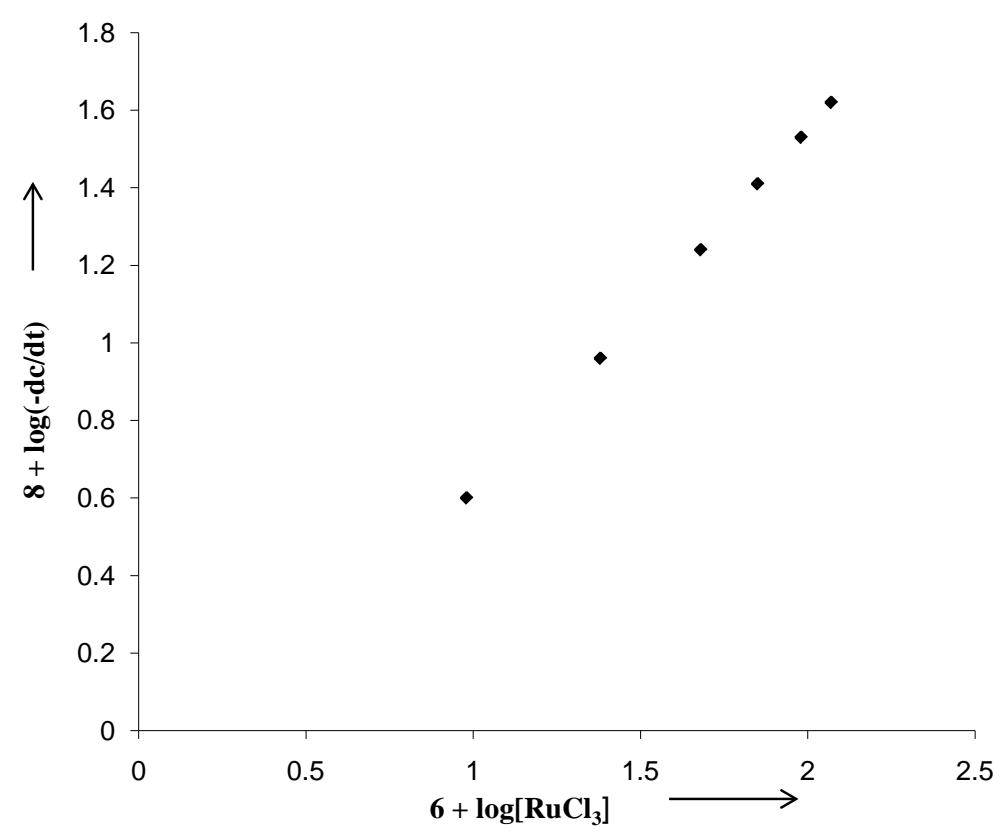

Plot between $\log (-d c / d t)$ and $\log [R u(I I I)]$ at $35^{\circ} \mathrm{C}$.

$\begin{array}{lll}{\left[\text { cyclohexanone }=1.00 \times 10^{-2} \mathrm{M}\right.} & {[\mathrm{KCl}]=1.00 \times 10^{-3} \mathrm{M}} \\ {\left[\mathrm{Hg}(\mathrm{OAc})_{2}\right]=1.25 \times 10^{-3} \mathrm{M}} & {\left[\mathrm{KBrO}_{3}\right]=1.00 \times 10^{-3} \mathrm{M}} \\ {\left[\mathrm{HClO}_{4}\right]=1.00 \times 10^{-3} \mathrm{M}} & \end{array}$

Figure A2. Plot between $8+\log (-\mathrm{dc} / \mathrm{dt})$ and $6+\log [\mathrm{Ru}(\mathrm{III})]$ for oxidation of cyclohexanone at $35^{\circ} \mathrm{C}$. 


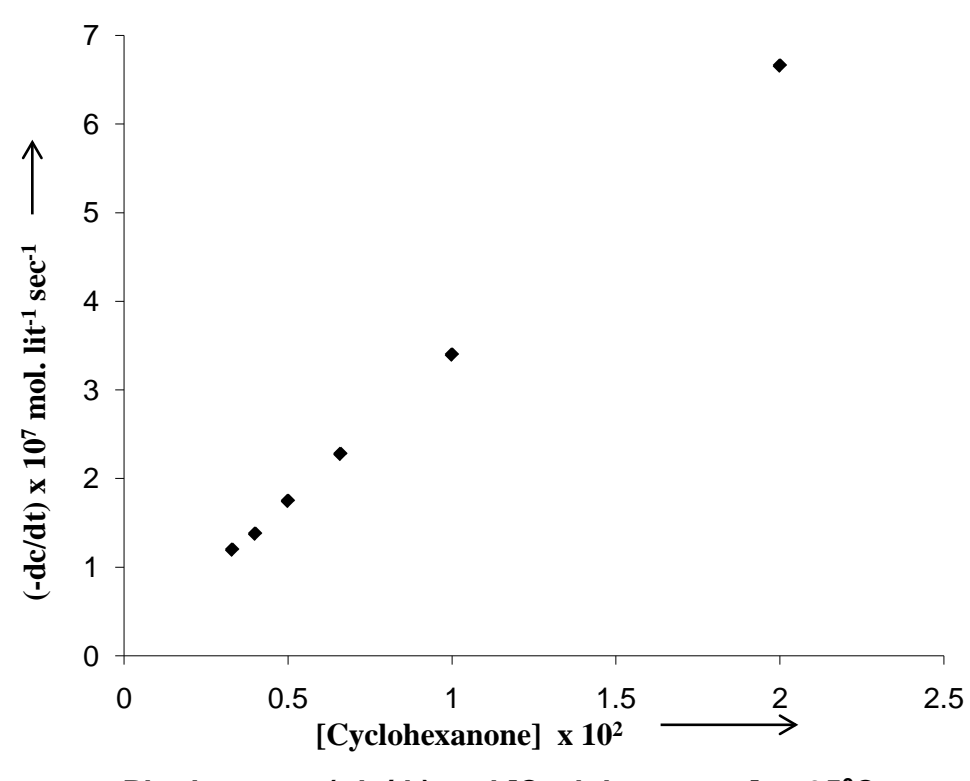

Plot between (-dc/dt) and [Cyclohexanone] at $35^{\circ} \mathrm{C}$.

$$
\begin{array}{lll}
{[\mathrm{KCl}]} & =1.00 \times 10^{-3} \mathrm{M} & {[\mathrm{KBrO}]=1.00 \times 10^{-3} \mathrm{M}} \\
{\left[\mathrm{Hg}(\mathrm{OAc})_{2}\right]} & =1.25 \times 10^{-3} \mathrm{M} & {[\mathrm{Ru}(\mathrm{III})]=96.00 \times 10^{-6} \mathrm{M}}
\end{array}
$$

Figure A3. Plot between $(-\mathrm{dc} / \mathrm{dt}) \times 10^{-7} \mathrm{ML}^{-1} \cdot \mathrm{s}^{-1}$ and [Cyclohexanone] $10^{-2}$ $\mathrm{M}$ for oxidation of cyclohexanone at $35^{\circ} \mathrm{C}$.

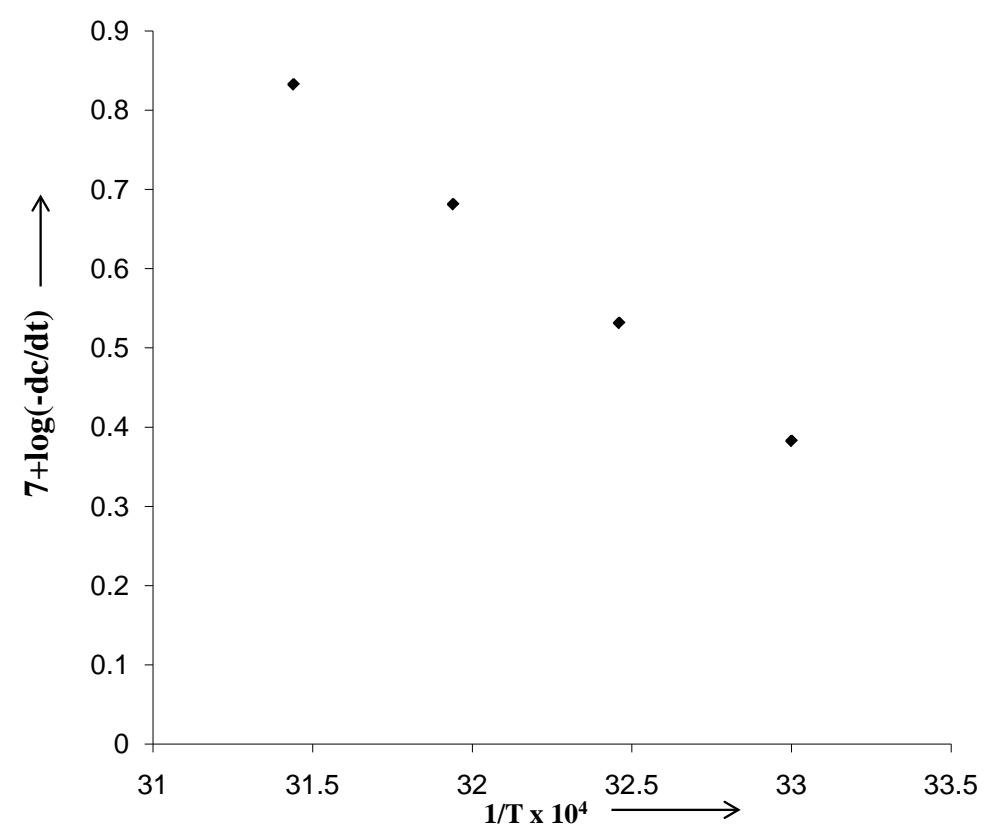

Plot of $\log (-d c / d t)$ Vs. 1/T

$$
\begin{array}{rlrl}
\text { cyclohexanone }=1.00 \times 10^{-2} \mathrm{M} & {[\mathrm{KCl}]} & =1.00 \times 10^{-3} \mathrm{M} \\
{\left[\mathrm{Hg}(\mathrm{OAc})_{2}\right]} & =1.25 \times 10^{-3} \mathrm{M} & {[\mathrm{Ru}(\mathrm{III})]} & =96.00 \times 10^{-6} \mathrm{M} \\
{\left[\mathrm{HClO}_{4}\right]} & =1.00 \times 10^{-3} \mathrm{M} & {\left[\mathrm{KBrO}_{3}\right]} & =1.00 \times 10^{-3} \mathrm{M}
\end{array}
$$

Figure A4. Plot between $7+\log (-\mathrm{dc} / \mathrm{dt})$ and $1 / \mathrm{T}$ for oxidation of cyclohexanone at $35^{\circ} \mathrm{C}$. 